\title{
Remoción de cefalosporinas con aluminosilicatos
}

\section{Removal of cephalosporins with aluminosilicates}

Zaira Magnolia Rivera-Pérez¹, Jonatan Torres-Pérez¹, Simón Yobanny Reyes-López ${ }^{1}$

1 Universidad Autónoma de Ciudad Juárez

\section{RESUMEN}

La presencia de contaminantes emergentes, como los antibióticos, representa una gran preocupación debido a los efectos que causa en los ecosistemas y la salud de los humanos. El mayor impacto de este tipo de contaminantes es la resistencia bacteriana en medios naturales, principalmente en el agua, y aunque existen métodos para removerlos, las trazas de antibióticos no pueden ser retiradas completamente por las plantas tratadoras de aguas residuales (PTAR). La adsorción es uno de los procesos para remover antibióticos del agua residual y los aluminosilicatos (Al-Si), naturales o modificados, son compuestos adsorbentes que no han recibido la suficiente atención, sin embargo, algunos estudios han demostrado su eficacia para remover antibióticos betalactámicos, como las cefalosporinas de primera, segunda, tercera y cuarta generación. Precisamente, esta familia de medicamentos es la principal causante de resistencia bacteriana en ambientes nosocomiales y naturales. El uso de Al-Si modificados con surfactantes, como bromuro de hexadeciltimetilamonio (HDTMA-Br), bromuro dodeciltrimetil amonio (DTAB) y nanopartículas de óxidos, es una alternativa promisoria para el tratamiento avanzado de aguas contaminadas con antibióticos. Algunas investigaciones han encontrado una mejora de $61 \%$ en el proceso de sorción de cefalexina con Al-Si modificados con nanopartículas metálicas y, por otro lado, un aumento del $65 \%$ en el proceso de remoción del mismo antibiótico cuando son modificados con $\mathrm{Fe}_{3} \mathrm{O}_{4}$. Lo anterior pone de manifiesto que la modificación superficial de los Al-Si mejoran considerablemente el proceso de adsorción de cefalosporinas.

PALABRAS CLAVE: aluminosilicatos; cefalosporinas; contaminantes emergentes; materiales adsorbentes.

\section{ABSTRACT}

The presence of emerging pollutants, such as antibiotics, is of great concern due to the effects it causes on ecosystems and human health. The greatest impact of this type of pollutant is bacterial resistance in natural environments, mainly in water, and although there are methods to remove them, traces of antibiotics cannot be completely removed by wastewater treatment plants (WWTP). Adsorption is one of the processes to remove antibiotics from wastewater and aluminosilicates (Al-Si), natural or modified, are adsorbent compounds that have not received enough attention, however, some studies have shown their efficacy to remove beta-lactam antibiotics, such as first, second, third, and fourth generation cephalosporins. Precisely, this family of drugs is the main cause of bacterial resistance in nosocomial and natural environments. The use of Al-Si modified with surfactants, such as hexadecyltimethylammonium bromide (HDTMA-Br), dodecyltrimethyl ammonium bromide (DTAB) and oxide nanoparticles, is a promising alternative for the advanced treatment of water contaminated with antibiotics. Some investigations have found a $61 \%$ improvement in the process of sorption of cephalexin with Al-Si modified with metallic nanoparticles and, on the other hand, a $65 \%$ increase in the removal process of the same antibiotic when they are modified with $\mathrm{Fe}_{3} \mathrm{O}_{4}$. This shows that the surface modification of Al-Si considerably improves the adsorption process of cephalosporins.

KEYWORDS: adsorbent materials; alumino-silicates; cephalosporins; emerging pollutants.

Correspondencia: Zaira Magnolia Rivera Pérez

Institución: Universidad Autónoma de Ciudad Juárez / Instituto de Ciencias Biomédicas (ICB)

Dirección: Av. Benjamin Franklin no. 4650, Zona Pronaf, Ciudad Juárez, Chihuahua, México, C. P. 32310

Correo electrónico: al194623@alumnos.uacj.mx
Fecha de recepción: Diciembre 10, 2020; Fecha de aceptación: Mayo 5, 2021. Fecha de publicación: Mayo 15, 2021.

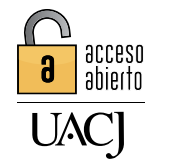




\section{INTRODUCCIÓN}

En los últimos años, la calidad del agua en los reservorios naturales se ha visto deteriorada de manera alarmante debido al crecimiento poblacional, la industrialización y demás actividades antropogénicas. No obstante lo anterior, en décadas recientes se han desarrollado tecnologías capaces de eliminar los contaminantes del agua y de igual forma mejorar la salud ambiental del entorno [1].

Los contaminantes emergentes, que abarcan productos farmacéuticos, son algunos de los compuestos que se puede encontrar en medios acuosos, causando impactos considerables en la salud humana y en el ambiente [1]-[4]. Un ejemplo de ello son los antibióticos, que por lo general una parte de estos se metaboliza en el organismo y el resto termina en los sistemas de agua municipales [3].

Existen diferentes métodos para controlar y reducir la contaminación por antibióticos en el agua [5], sin embargo, la mayoría de estos son costosos desde el punto de vista operativo y de mantenimiento, e incluso algunos suelen tener subproductos tóxicos o de difícil manejo ${ }^{[4], ~[6] . ~ E n ~ p l a n t a s ~ d e ~ t r a t a m i e n t o ~ d e ~ a g u a s ~ r e s i d u a-~}$ les (PTAR) se utilizan procesos biológicos para reducir la materia orgánica y los nutrientes, pero a pesar de ello solo una pequeña cantidad de estas utilizan medios avanzados de desinfección adicionales (tratamiento terciario), como los rayos ultravioleta (UV), el procedimiento con ozono o la membrana de filtración para eliminar específicamente los microorganismos [7], [8].

En México, la Comisión Nacional del Agua, en su informe de 2019, reportó que del total de 2642 PTAR en el territorio nacional, solo un $0.2 \%$ (4 plantas) realiza tratamiento terciario ${ }^{[9]}$. En algunas de estas plantas se aplican procesos de adsorción para eliminar contaminantes disueltos que quedan de las fases anteriores o después de tratamientos de oxidación química [5], [10]. Cuando la eliminación es ineficiente, se puede provocar problemas de salud y efectos adversos en los seres vivos, ya que se puede desarrollar cepas de microorganismos multirresistentes ${ }^{[11]}$.

En las últimas décadas, varias revisiones de literatura [1], [4], [6], [8], [12]-[14] han abordado el uso de adsorbentes de bajo costo, entre ellos los minerales arcillosos o las mezclas minerales, por ejemplo, la bentonita (componente principal: montmorillonita) o tierra de Fuller (atapulgi- ta y variedades de montmorillonita), para eliminar productos farmacéuticos, como los antibióticos presentes en aguas residuales. De esto deriva la importancia de conocer a fondo los diferentes materiales usados en los últimos años en el tratamiento avanzado de agua contaminada con antibióticos. De manera específica, el presente documento presenta una revisión sobre la investigación existente en torno al uso de Al-Si para remover cefalosporinas de medio acuoso, lo cual convierte a dichos materiales en alternativas viables y altamente sostenibles en tratamientos avanzados de aguas contaminadas.

Para hacer este trabajo, se llevó a cabo una revisión de los últimos 15 años (2005-2020) en las bases de datos EBSCOhost, ScienceDirect y ACS Publications, entre otras, mediante búsquedas con las palabras clave indicadas al final del resumen del presente documento. Enseguida, se comparó y jerarquizó la información recabada, con base en la relevancia y la pertinencia sobre la problemática de la contaminación con cefalosporinas y su remoción con aluminosilicatos.

\section{ANTIBIÓTICOS COMO CONTAMINANTES EMERGENTES}

Diversos productos se elaboran diariamente alrededor del mundo, provocando el aumento de las emisiones de contaminantes químicos al ambiente. Algunos pueden ser tóxicos, persistentes y bioacumulables. Los contaminantes emergentes son aquellos productos cuyas fuentes de emisión no han sido estudiadas de forma detallada y no hay aún, en la mayor parte de ellos, estudios acerca de su toxicidad y persistencia en el ambiente. Algunos de estos son los fármacos, productos de uso personal, surfactantes y derivados de procesos industriales [2].

Varios estudios han demostrado que los contaminantes emergentes, que probablemente han estado presentes en el ambiente desde empezaron a ser usados por los humanos, se encuentran en aguas residuales, superficiales, subterráneas y entornos marinos [15].

Los compuestos farmacéuticos no estaban catalogados como contaminantes emergentes, debido a que la información referente a su acumulación y moléculas de transformación en el ambiente y seres vivos no estaba referenciada, principalmente en cuerpos de agua. Sin embargo, a inicios de los años noventa se empezaron a detectar y cuantificar en concentraciones de partes por millón (ppm) y partes por billón (ppb) [16]. 
Se ha reportado que en países de la Unión Europea (España, Italia, Alemania, Grecia y Francia) y del continente americano (Canadá y Brasil), hay efluentes de aproximadamente 900 toneladas de productos farmacéuticos por año [17], en donde algunos, como los analgésicos, han alcanzado concentraciones de 0.22 y 3.02 $\mu \mathrm{g} / \mathrm{L}$, respectivamente. Por otro lado, en Alemania hay reportes de concentraciones de compuestos farmacéuticos de antiinflamatorios mayores a $2.00 \mu \mathrm{g} / \mathrm{L}$ en aguas tratadas [16], [18].

Diversas causas, entre ellas la demanda, la periodicidad de administración, la medicación sin supervisión y los procesos fisiológicos, repercuten en la cantidad y la permanencia de los principios activos en el agua. Los medicamentos administrados no son totalmente absorbidos por el cuerpo, sino que una parte se excreta y llega a las aguas residuales y superficiales [16]. En algunos países, como Alemania, una considerable cantidad de principios activos farmacéuticos de uso frecuente en la población son incorporados al ambiente [19].

De igual forma, los sistemas hospitalarios añaden productos antimicrobianos a los sistemas de agua municipales, suscitando la generación de microorganismos resistentes y modificaciones en la actividad enzimática de la microbiota, lo cual modifica los procesos de biodegradación adecuada de materia orgánica en los cuerpos de agua [20].

Los antibióticos se han convertido en contaminantes importantes debido a su uso generalizado y a los efectos biológicos en la biota [8], [21], [22]. Estos compuestos farmacéuticos muestran "pseudo-persistencia" en formas nativas o en metabolitos, los cuales se incorporan al ambiente a través de excretas, de la fabricación industrial o de medicamentos sin utilizar o caducos [25], convirtiéndose así en contaminantes ambientales [8], [23], [24]. En países como China, Canadá, Alemania, Italia, Japón, Suiza y los Estados Unidos, los antibióticos han sido detectados en concentraciones desde ng/L hasta $\mu \mathrm{g} / \mathrm{L}[8]$, [22].

La eliminación eficiente de los antibióticos y sus metabolitos en las PTAR varía en función de los procesos de tratamiento empleados; la edad de lodos activados; el tiempo de retención hidráulica; las condiciones ambientales, entre ellos temperatura e intensidad de luz; y las propiedades físicas, incluyendo la capacidad de adsorción del compuesto en lodos [25], [26].
El uso de antibióticos de amplio espectro, como las cefalosporinas, ha originado la prevalencia de bacterias resistentes a los antibióticos (AMR, por sus siglas en inglés) no solo en humanos y animales, sino también en el ambiente, por ejemplo, en aguas superficiales y suelos. Como consecuencia, la probabilidad de exposición a las AMR ha aumentado fuera de un entorno de atención médica ${ }^{[7]}$.

\section{CEFALOSPORINAS RESISTENTES A ANTIBIÓTICOS}

La abundancia y propagación de genes de resistencia a antibióticos (ARG) y bacterias AMR en el ambiente se ha incrementado, en parte por el uso intensivo de antibióticos betalactámicos en medicina humana y veterinaria [4], [27], [28]. La diseminación de bacterias con resistencia adquirida a los antimicrobianos puede representar riesgos directos e indirectos para la salud humana: los primeros implican la exposición a patógenos de AMR, lo que resulta en infecciones difíciles de tratar, y los segundos están asociados a la exposición a bacterias comensales que pueden colonizar el intestino, la piel o las mucosas. Los riesgos para la salud pública relacionados con el transporte asintomático comprenden la transferencia de genes de resistencia a personas que son más vulnerables a infecciones, entre ellos ancianos, personas inmunodeprimidas y aquellas con enfermedades subyacentes ${ }^{[7]}$.

Las personas pueden exponerse a las moléculas de antibióticos a través de la preparación y el consumo de productos cárnicos [29] y lácteos [30], así como alimentos crudos [31] contaminados, o por contacto e ingestión de aguas superficiales contaminadas durante actividades recreativas ${ }^{[32]}$. De igual manera, el agua superficial destinada al riego de cultivos que contiene ARG y AMR podría permitir su transferencia a diferentes compartimentos ambientales. Por lo tanto, podría ser posible una transferencia desde las PTAR, a través del agua, a los animales o los alimentos y, finalmente, a los hogares, a los humanos [33]. En este sentido, los betalactámicos, entre ellos las cefalosporinas de tercera generación, son de particular interés porque estos antibióticos son antimicrobianos de importancia crítica.

En algunas investigaciones se han enumerado, aislado y caracterizado fenotípicamente las enterobacterias con resistencia a 13 antibióticos [34]. Los resultados revelaron una alta frecuencia de resistencia al grupo de 
cefalosporinas, como cefoxitina (53.5\%), cefotaxima (22.7\%), cefpiroma (19.2\%) y ceftazidima (16.2\%). El efluente hospitalario estudiado mostró las mayores tasas de bacterias con resistencia a todos los antibióticos $y$, de manera similar, se detectaron tasas de resistencia más altas en bacterias del efluente de una PTAR en comparación con el efluente sin tratar [34].

Respecto a la contaminación de fuentes de agua subterránea, las tasas de contaminación por resistencia a antibióticos de 11 pozos, 5 arroyos y 4 plantas de tratamiento ubicadas en el área de Oltrepò Pavese, Francia, fueron determinadas para detectar la presencia de bacterias Gram negativas resistentes a cefalosporinas de tercera generación, como la cefotaxima [35]. En el caso de 132 aislados de enterobacterias que crecieron en agar MacConkey con cefotaxima, 82 (62.1\%) se obtuvieron de corrientes, $41(31.1 \%)$ de plantas de tratamiento y $9(6.8 \%)$ de pozos. Y de ese total de aislamientos, 30 pertenecieron a Escherichia coli. Los resultados de resistencia bacteriana son de preocupación de salud pública, pues destacan la necesidad de mejorar las medidas higiénicas para reducir la carga de bacterias vertidas con mecanismos de resistencia emergentes.

Investigaciones en el análisis de datos en Europa y América han mostrado que el espectro de beta-lactamasas, producido por E. coli y K. pneumoniae, es susceptible a cefalosporinas de cuarta generación (cefepime) en $39.6 \%$ y $51.4 \%$ de los casos [36]. En la región de Asia-Pacífico se expresa la susceptibilidad a cefepime entre el 33 y el $93 \%$ para E. coli y del 25 al $100 \%$ para K. pneumoniae. También se encontró que el cefepime se elimina principalmente por vía renal como fármaco activo inalterado y la recuperación urinaria de cefepime intacta es aproximadamente el $80 \%$ de la dosis administrada, por lo que puede entrar de manera directa a los sistemas de aguas residuales. Existe una creciente preocupación pública con respecto al destino de los ARG durante el tratamiento de aguas residuales, su persistencia durante el proceso de tratamiento, así como sus posibles impactos en los cuerpos de agua receptores.

En un estudio realizado en efluentes de PTAR de diez países europeos diferentes, se detectaron ARG en todas las muestras de efluentes y aguas de río, lo cual demuestra que las plantas de tratamiento de aguas residuales europeas contribuyen al enriquecimiento del resistoma (colección de todos aquellos genes que fomentan la resistencia bacteriana) en los cuerpos de agua receptores [37].
En los últimos 15 años se ha observado un incremento en la multirresistencia en diversas comunidades de bacterias frente a antibióticos beta-lactámicos. Las aguas residuales de hogares y las escorrentías agrícolas y de hospitales reciben estos antibióticos y se considera un punto de acceso a los sistemas de aguas superficiales [33]. En este medio, la mayoría de los antibióticos no se puede eliminar de manera efectiva con un proceso de tratamiento tradicional antes de ser liberados al ambiente [38]. En países como Holanda, de las 352 PTAR existentes, la mayoría utiliza procesos de tratamiento biológico que reducen la materia orgánica y nutrientes y solo una minoría pone en práctica procesos adicionales de desinfección, como UV, ozono o filtración por membrana para la remoción de contaminantes específicos [7], [39].

\section{MÉTODOS DE REMOCIÓN DE ANTIBIÓTICOS}

Existen varios métodos de remoción de contaminantes de origen orgánico, entre ellos los antibióticos, pero a veces los costos tienen una importancia primordial en la elección de la forma de control de la contaminación, por lo cual se busca una tecnología rentable para la seguridad y el tratamiento eficaz de las aguas residuales. Entre las alternativas de remoción se encuentran la filtración; la ósmosis inversa; el intercambio iónico; la oxidación usando cloro, ozono, peróxido de hidrógeno y dióxido de cloro como agentes oxidantes; la adsorción; las reacciones fotoquímicas; los lodos activados y los tratamientos aeróbico y anaeróbico, por mencionar algunos [40]. La mayoría de estas tecnologías se emplea para el control de contaminantes específicos, sin embargo, los procesos de adsorción, al no ser específicos, se pueden utilizar para remover o reducir varios contaminantes. Por ser un tratamiento eficaz de remoción de subproductos o contaminantes, fácil de operar y de mayor aplicabilidad, se ha reconocido la importancia de la adsorción en las industrias química, alimentaria, petrolera y farmacéutica.

\section{ADSORCIÓN: TRATAMIENTO AVANZADO DE AGUAS RESIDUALES}

El término adsorción se introdujo por primera vez en 1881 para diferenciar la acumulación superficial de la penetración intermolecular [40]. Se postuló que su característica básica es la acumulación de material en la superficie o interfaz (Figura 1). En el caso del tratamiento de aguas, el proceso de adsorción se produce en una 
interfaz entre el adsorbente sólido y agua contaminada llamada fase adsorbente. La fase sólida de los adsorbentes se caracteriza por sitios activos ricos en energía que pueden interactuar con el adsorbato (contaminante) en la fase líquida debido a su especificidad electrónica y características espaciales (Figura 1) [41], [42].

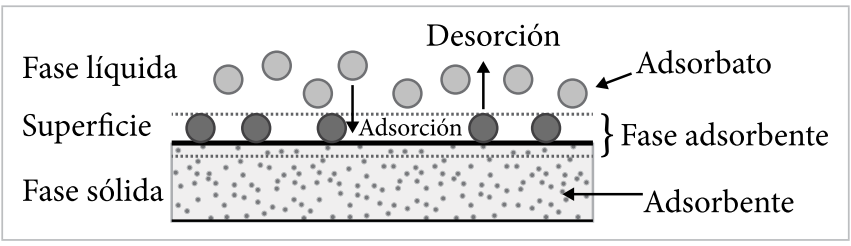

Figura 1. Proceso de adsorción (modificado de ${ }^{[42]}$ ).

Hoy en día es habitual diferenciar entre dos tipos de adsorción. Si la atracción entre la superficie sólida y las moléculas adsorbidas son de naturaleza física, se le conoce como adsorción física. Generalmente, son fuerzas de van der Waals y, como son débiles, la adsorción resultante es de naturaleza reversible, por lo que puede tener un proceso de desorción. Por otro lado, si las fuerzas de atracción entre las moléculas adsorbidas y la superficie sólida surgen debido a un enlace químico, el proceso se llama quimisorción [40], [43]. El intercambio de iones es un proceso químico reversible en el que un ion de la solución se intercambia por un ion con carga similar unido a una partícula sólida inmóvil. La aplicación del intercambio iónico al tratamiento del agua potable se encuentra en el área del ablandamiento, es decir, la eliminación de calcio, magnesio y otros cationes polivalentes a cambio de sodio ${ }^{[44]}$.

\section{MATERIALES ADSORBENTES}

La propiedad más importante que debe tener un adsorbente es una estructura porosa que da como resultado un área superficial alta, además de poseer un equilibrio de adsorción en el menor tiempo posible para que pueda eliminar los contaminantes en un tiempo reducido. Es por ello que se buscan adsorbentes con alta área superficial, porosidad y que muestren una cinética de adsorción rápida ${ }^{[42]}$.

Investigaciones previas proponen diferentes materiales que pueden ser usados para remover productos farmacéuticos de aguas residuales por medio de adsorción, tales como alúmina, bauxita, gel de sílice, carbón activado, resinas de intercambio iónico y aluminosilicatos como las zeolitas [6], [45]. La adsorción es considerada como el mejor método de tratamiento para aguas residuales. Debido a su carácter universal, bajo costo y facilidad de operación, este método puede eliminar compuestos solubles e insolubles hasta en un 99.9\% [1], [6], [8].

La alúmina es un cerámico poroso sintético que está disponible en forma de gránulos de diferentes tamaños. Se usa en industrias que requieren eliminar agua en corrientes de gas, decoloración y refinación de ceras y aceites de petróleo. Por otro lado, la bauxita es una alúmina cristalina porosa de origen natural mezclada con caolinita y óxidos de hierro en proporciones variables, según el lugar de origen. Se usa ampliamente en lugar de la alúmina y se ha demostrado experimentalmente que elimina la mayoría de las bacterias aeróbicas y anaeróbicas [46]. Otro material adsorbente es el gel de sílice, el cual se prepara mediante la coagulación de ácido silícico coloidal, lo que da como resultado la formación de gránulos porosos y no cristalinos de diferentes tamaños, y muestra una superficie superior en comparación con la alúmina $\left(250 \mathrm{~m}^{2} \mathrm{~g}^{-1}\right)$ [47]. El gel se considera un buen adsorbente y se utiliza en muchas industrias de secado de gases y líquidos y depuración de hidrocarburos [47].

El carbón activado es el adsorbente más antiguo y utilizado que se conoce; por lo general se prepara de carbón, cáscaras de coco, lignito y madera, y comúnmente se utiliza para eliminar diversos contaminantes del agua, como tintes y metales pesados [48], [49]. Sin embargo, su uso en aguas residuales a veces está restringido debido a su mayor costo, la capacidad de regeneración o la eliminación del adsorbente al final de su ciclo de uso [50]. Para el tratamiento del agua, este adsorbente está disponible en dos formas principales: carbón activado en polvo (PAC) y carbón activado granular (GAC).

Además, las zeolitas son materiales también usados ampliamente en estos procesos. Son silicatos cristalinos capaces de sufrir reacciones reversibles de intercambio de bases, se pueden formar fusionando cantidades de feldespato, arcilla y carbonato de sodio, y se caracterizan por ser adsorbentes microporosos importantes que se producen de forma natural o sintética. Las zeolitas sintéticas son obtenidas a partir de mezclas de sosa cáustica, silicato de sodio y bauxita ${ }^{[6]}$. Las zeolitas naturales generalmente tienen un área superficial baja, sin embargo, la superficie aparente de algunas zeolitas sintéticas puede llegar a $700 \mathrm{~m}^{2} \mathrm{~g}^{-1}[40]$. 
Por último, las resinas se utilizan como adsorbente a través de un mecanismo de intercambio catiónico o aniónico: las primeras contienen grupos de ácido sulfónico unidos o grupos carboxílicos, por ejemplo, poliestireno sulfonato, resina fenólica sulfonada, fosfonato de poliestireno y poliestireno amidoxima, y las segundas generalmente tienen grupos de amonio cuaternario u otros grupos amino e incluyen trimetil bencil amonio a base de poliestireno, epoxi-poliamina y aminopoliestireno. Las resinas se han utilizado con bastante eficacia para la eliminación de sustancias orgánicas específicas [40], [46].

Se ha examinado una gran variedad de adsorbentes de bajo costo por su capacidad de remover varios tipos de contaminantes de aguas residuales, lo cual proporcionaría una doble ventaja: la reducción de subproductos (o desechos) y el desarrollo de adsorbente de bajo costo para reducir la contaminación de las aguas residuales a un precio razonable [1], [50], [51].

En cuanto a los costos de operación, hay datos estimados de algunas técnicas de remoción de contaminantes en las que se compara la electrocoagulación contra la coagulación química con flotación por aire disuelto, y se reporta que se incrementan conforme la corriente aumenta, en tanto que los correspondientes al consumo de los electrodos de aluminio fluctúan de un 70 a $90 \%$ del costo total [52]. Otras investigaciones resaltan que los costos por concepto de material de electrodos, cuando se emplea aluminio para técnicas electroquímicas, es de 7 dólares canadienses (CAD) por kilogramo, lo que para dosificaciones de $81 \mathrm{mg} \mathrm{Al} / \mathrm{L}$ genera un costo del agua tratada (solo por material de electrodos) de CAD $0.57 / \mathrm{m}^{3}[53]$.

En un estudio realizado en la Comarca Lagunera en México, en un pozo contaminado con arsénico que produce $2500 \mathrm{~m}^{3} /$ día de agua, el costo de energía es de USD 0.002 por metro cúbico de líquido, usando una tecnología de electrocoagulación. El costo de tratar el agua en este sistema es directamente proporcional a la cantidad y el tipo de contaminantes ${ }^{[54]}$.

Por otro lado, la síntesis de 5.0 g por lote de aluminosilicatos tipo zeolitas, requirió un gasto 20 veces menor de energía en comparación con un método convencional [55]. Una preparación económica similar de zeolitas adsorbentes, realizada en la India, indica que la variedad más económica comercialmente de carbón cuesta 350 USD/ton y el costo de zeolitas sintetizadas se estima en
150 USD/ton, el cual es menor en comparación con el carbón activado comercial disponible en el mercado [56]. Los hallazgos conducen a posibles adsorbentes rentables para eliminar compuestos orgánicos de aguas residuales, que contribuyen a una reducción de costos para la realización de un proceso sostenible y ambientalmente amigable [55].

\section{REMOCIÓN DE ANTIBIÓTICOS CON ZEOLITAS}

La posibilidad de usar adsorbentes de origen mineral de bajo costo, como las zeolitas, ha sido estudiada en tratamientos posteriores al proceso secundario para la eliminación de hidrocarburos aromáticos policíclicos (HAP) y en compuestos fenólicos como el naftaleno, fenantreno y benzopireno [57], [58].

Las zeolitas son silicatos que pueden encontrarse de forma natural, pero también se pueden sintetizarse a nivel comercial. De las 40 categorías existentes, la clinoptilolita es una de las más abundantes y usada para procesos de remoción de contaminantes [1], [6]. Las propiedades de adsorción de las zeolitas dependen de sus capacidades de intercambio iónico, lo cual puede ser mejorado con la modificación superficial con surfactantes catiónicos, por ejemplo, el HDTMA-Br (bromuro de hexadeciltrimetilamonio) o DTAB (bromuro de dodeciltrimetilamonio) [59], [60] e incluso con nanopartículas de metales de transición, como la plata ${ }^{[61]}$.

Las propiedades de las zeolitas varían con la relación molar de Si y Al. Las que son bajas en sílice (relación $\mathrm{Si} / \mathrm{Al}<2$ ) poseen una alta capacidad de intercambio iónico y por lo tanto se han utilizado para el ablandamiento de agua. Las altas en sílice son adsorbentes eficientes para eliminar compuestos orgánicos [62]. La caracterización de zeolitas se lleva a cabo generalmente aplicando diversas técnicas, como rayos X, IR, Raman y microscopía electrónica de barrido, entre otras [40].

Los distintos tipos de zeolitas naturales deriva de la forma en que los tetraedros pueden vincularse en el espacio en una, dos o tres dimensiones, y desde el tipo de otros iones que sustituyen dentro de los intersticios. Los tetraedros de oxígeno están dispuestos en 4, 5 o 6 anillos de 8 y 12 miembros, comúnmente llamados Unidades de Construcción Secundaria (SBU) (Figura 2), que se combinan para formar los canales y cavidades de las distintas zeolitas (Figura 3) [63]. Un anillo de 8 se consi- 
dera una abertura de poro pequeño; uno de 10, de poro mediano; y uno de 12, de poro grande. Con diámetros libres (calculado utilizando un radio de oxígeno de 1.35 Å) de aproximadamente 4.1, 5.5 y $7.4 \AA$, respectivamente [64]. No obstante, los anillos se pueden distorsionar, por lo que estos números solo deben utilizarse como una guía aproximada. Es por ello que algunos autores consideran a los aluminosilicatos como materiales microporosos [62].

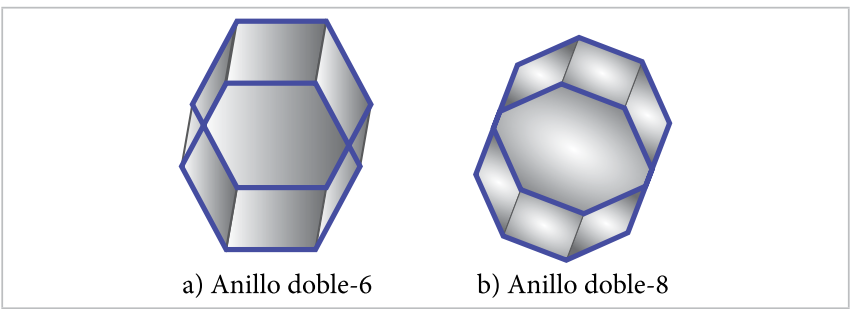

Figura 2. Combinación de canales y cavidades (modificado de $[63]$.

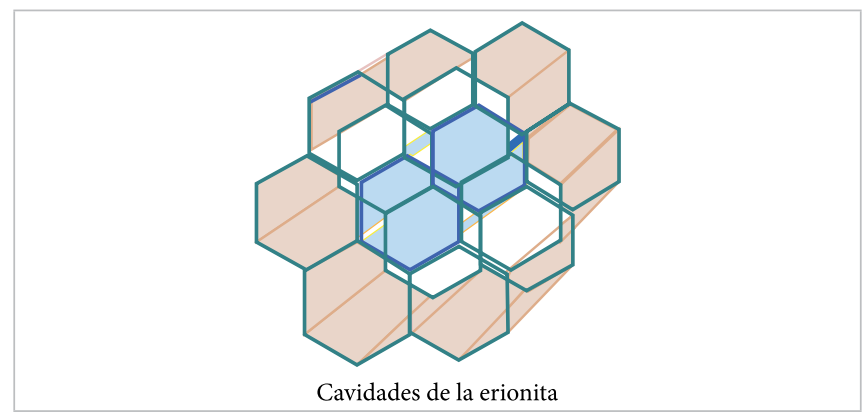

Figura 3. Ejemplo de conformación de SBU (modificado de [63]).

En cuanto a la remoción de antibióticos con materiales inorgánicos con Al-Si, como las zeolitas, ha demostrado que una zeolita natural tiene un $28 \%$ de eficiencia para remover la cefalexina, mientras que en una zeolita superficialmente con óxido de manganeso y bromuro de cetiltrimetilamonio (CTAB) es de $89 \%$ [53].

Otras investigaciones han evaluado la eficacia de adsorción de farmacéuticos con grupos orgánicos como las $\mathrm{N}$-nitrosaminas y sulfamidas [65], [66]. En comparación con otros absorbentes, las zeolitas con alto contenido de sílice presentaron una alta capacidad de adsorción en monocapa para otros compuestos, por ejemplo, el triclosán (378 $\left.\mathrm{mg} \mathrm{g}^{-1}\right)$, cuya capacidad de adsorción aumenta respectivamente con la superficie de los poros.

En un material adsorbente, los poros se pueden clasificar en tres grupos: microporos $(<2 \mathrm{~nm})$, mesoporos $(2-50 \mathrm{~nm})$ y macroporos (>50 nm) [67]. Sin embargo, en aluminosilicatos sintetizados, la abertura de estos está definida por el tamaño del anillo que define su estructura, donde $n$ es el número de átomos de $T$ ( $T$ es cualquier catión coordinado tetraédricamente) en el anillo [63].

Los Al-Si, como la arcilla, con superficie de poros pequeña, han demostrado ser menos eficientes para la adsorción de triclosán [68]. Cabe señalar que en algunos trabajos se ha indicado que los procesos de modificación superficial pueden inducir un aumento o disminución - en el área de la superficie- del tamaño de los poros de la montmorillonita, teniendo un efecto en la selectividad en el proceso de adsorción de compuestos orgánicos [69].

La adsorción de antibióticos - por ejemplo, la tetraciclina- en arcillas está muy influenciada por el $\mathrm{pH}$, la fuerza iónica y cationes orgánicos disueltos. En aluminosilicatos, el intercambio catiónico se considera el principal mecanismo de adsorción y en el caso de las tetraciclinas la adsorción generalmente disminuye al aumentar el $\mathrm{pH}$ [70]. El uso de tensoactivos como modificador de superficie puede cambiar el área hidrofílica a una más hidrofóbica, mejorando a la sorción de contaminantes orgánicos debido a los conglomerados que forma con los grupos alquilo del tensoactivo ${ }^{[69]}$.

Hay una relación entre el diámetro de Stokes de los productos farmacéuticos y las nitrosaminas, lo que indica que es más probable un mecanismo de adsorción de "ajuste perfecto" que la interacción hidrofóbica en estas zeolitas. De igual manera, debido a su naturaleza selectiva, la adsorción en zeolitas únicamente debe considerarse como un tratamiento adicional a procesos existentes [71].

\section{REMOCIÓN DE CEFALOSPORINAS CON Al-Si}

Las cefalosporinas son antibióticos que pertenecen al grupo de los B-lactámicos (Figura 4). Son derivados de 7-aminocefalos ácido poránico (7-ACA) y contienen el grupo cefem que consta de anillos de lactama y dihidrotiazina (Figura 5). Las llamadas cadenas laterales R, R1 y R2, pueden tener una variedad de estructuras químicas, de lo cual derivan todas las demás estructuras de esta familia (Figura 6) [72]. La actividad antimicrobiana, estabilidad química, solubilidad y propiedades ácido-base de los antibióticos de esta familia dependen en gran medida de su estructura [73]. 


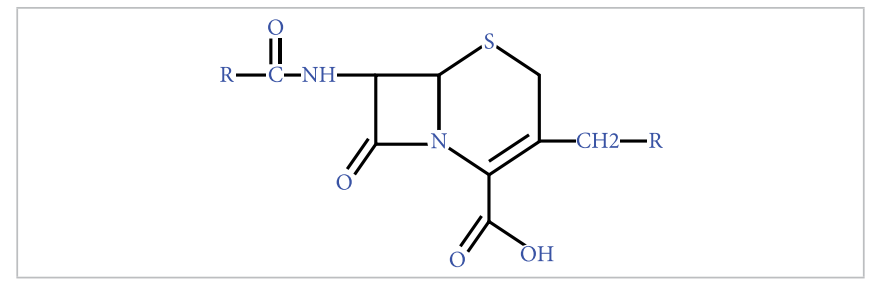

Figura 4. Estructura básica de una cefalosporina (modificada de ${ }^{[73]}$ ).

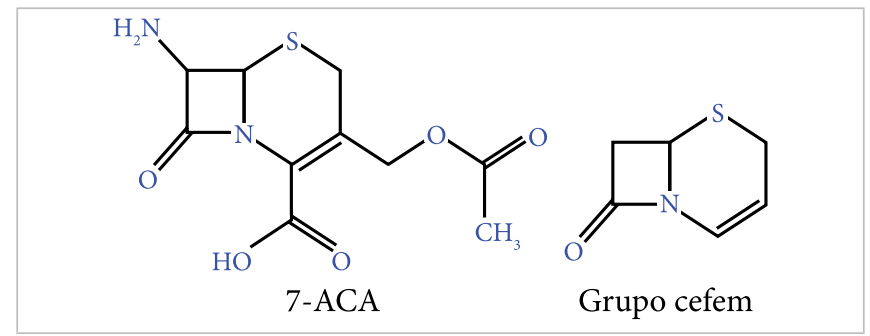

Figura 5. Derivación de cefalosporinas (modificada de ${ }^{[73]}$ ).

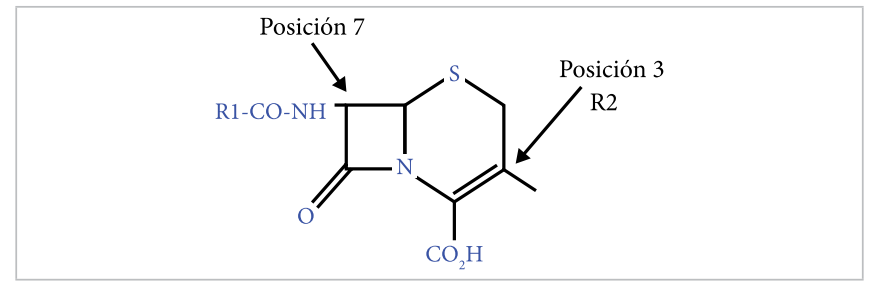

Figura 6. Núcleo cefem (tomada de ${ }^{[72]}$ ).

En medicina humana, las cefalosporinas se utilizan principalmente para tratar infecciones específicas del tracto genital e infecciones graves como la meningitis
[74]. Por otra parte, en la medicina veterinaria las cefalosporinas son ampliamente utilizadas en infecciones del tracto y las alteraciones intramamarias ${ }^{[75]}$. Una vez dentro del cuerpo humano o animal, el exceso de antibióticos y/o sus metabolitos puede seguir tres rutas principales: 1) distribuirse en hígado, riñón y músculos; 2) ser secretado en leche o 3 ) excretarse con heces y orina [75], [76].

El núcleo de las cefalosporinas es resistente a muchas penicilinasas; por lo tanto, las bacterias que producen estas enzimas son susceptibles a la acción de las cefalosporinas y esta característica otorga su amplio espectro de actividad antimicrobiana.

Las cefalosporinas son utilizadas como agentes de primera elección en el tratamiento de una serie de infecciones nosocomiales. No obstante, el uso creciente de esta clase de antibióticos se ha asociado a la presencia de bacterias resistentes [72], [73], [77].

Derivado del riesgo potencial que representan estas moléculas farmacéuticas cuando están presentes en cuerpos de agua, es primordial la eliminación de las mismas por métodos avanzados de tratamiento que provoquen una remoción total por medio de procesos altamente efectivos. Algunos de los diferentes métodos que existen actualmente para remoción de cefalosporinas se describen en la Tabla $1{ }^{[78]}$.

TABLA 1

Tecnologías Usadas para la Remoción de Cefalosporinas

\begin{tabular}{|c|c|c|c|c|}
\hline Antibiótico & GENERACión & TECNOLOGÍA DE REMOCIÓN & $\begin{array}{c}\text { EFECTIVIDAD DEL } \\
\text { PROCESO }\end{array}$ & REF. \\
\hline Cefalexina & Primera & $\begin{array}{l}\text { Zeolitas } \\
\text { Electrólisis } \\
\text { Fotocatálisis } \\
\text { Zeolitas con óxido de manganeso }\end{array}$ & $\begin{array}{l}16.10 \mathrm{mg} / \mathrm{g} \\
90 \%>, \mathrm{C}_{0}=0.1 \mathrm{~g} \mathrm{~L}^{-1} \\
76 \%, \mathrm{C}_{0}=0.2 \mathrm{~g} \mathrm{~L}^{-1} \\
24.5 \mathrm{mg} / \mathrm{g}\end{array}$ & $\begin{array}{l}{[79]} \\
{[80]} \\
{[81]} \\
{[80]}\end{array}$ \\
\hline Cefalotina & Primera & Fotocatálisis & $72.8 \%, \mathrm{C}_{0}=50 \mu \mathrm{M}$ & {$[82]$} \\
\hline Cefuroxima & Segunda & Fotólisis & $80 \%, \mathrm{C}_{0}=0.5 \mathrm{~g} \mathrm{~L}^{-1}$ & [83] \\
\hline Cefexime & Tercera & $\begin{array}{l}\text { Óxido de manganeso } \\
\text { Nanopartículas }\end{array}$ & $171.60 \mathrm{mg} / \mathrm{g}$ & [84] \\
\hline Cefaloxina & Primera & Cloración & No reportado & {$[85]$} \\
\hline Ceftriaxona & Tercera & Fotólisis & $80 \%, \mathrm{C}_{0}=0.5 \mathrm{~g} \mathrm{~L}^{-1}$ & [83] \\
\hline Cefepime & Cuarta & Fotólisis & $80 \%, \mathrm{C}_{0}=0.5 \mathrm{~g} \mathrm{~L}^{-1}$ & [83] \\
\hline
\end{tabular}

El uso de zeolitas naturales para la remoción de cefalexina aumenta significativamente (de 28 a $89 \%$, pH 7) cuando se recubren nanopartículas de óxido de manganeso ${ }^{[79]}$. Del mismo modo, la adsorción de cefalexina 
y cefexima sobre nanopartículas de óxido de magnesio ( $\mathrm{pH} 9 ; \mathrm{T}=20^{\circ} \mathrm{C}$ ) se ve aumentada con el uso de este material (la cefexima presenta un máximo de adsorción en $\mathrm{MgO}$ a valores de $\mathrm{pH}$ más altos) [84]. Dichas investigaciones muestran mecanismos de adsorción que son mejorados con la presencia de nanopartículas metálicas en un valor de $\mathrm{pH}$ entre 7 y 9.

Las soluciones ácidas, ambos grupos carboxilo y los grupos amino de los adsorbentes zeolíticos están protonados y debido a la competencia de los protones por unirse a los sitios activos y el efecto repulsivo de la superficie cargada positivamente para la unión de cefalexima, se explica la disminución de la eficiencia de eliminación bajo condiciones ácidas [79].

Se han realizado estudios sobre el mecanismo de adsorción de cefapirina (un antibiótico de primera generación usado en el ganado vacuno de la industria lechera) sobre superficies inorgánicas como aluminosilicatos $(\mathrm{pH}$ 4.7; $\mathrm{T}=23^{\circ} \mathrm{C}$ ). En ese trabajo se demostró el papel del estado iónico de las cefalosporinas y su relación con el $\mathrm{pH}$, mostrando que el proceso de adsorción ocurre por atracción electrostática del grupo anión carboxilato $(-\mathrm{COO})$ a $\mathrm{pH}$ bajo, $\mathrm{y}$ de igual forma pueden operar mecanismos similares para otras cefalosporinas con características zwitteriónicas, como es la cefapirina, la cual es $53 \%$ catiónica y $47 \%$ zwiteriónica, característica que provoca una atracción electrostática entre el COO- del antibiótico y la superficie del adsorbente [86].

Algunos tipos de cefalosporinas contienen un aminotiazol y dos grupos carboxílicos, los cuales poseen tres constantes de disociación $(K)$ que corresponden a la disociación del grupo carboxílico unido al grupo cefem $(K 1)$, la disociación del grupo carboxílico de cadena lateral (K2) y la disociación del protón coordinado con el anillo tiazol (K3). Estos grupos son afectados por los cambios de $\mathrm{pH}$, modificando el proceso de adsorción [73].

Adicionalmente, se ha investigado la eliminación de cefalexina (CEX) de una solución acuosa, mediante zeolita natural (NZ) y nanopartículas magnéticas de $\mathrm{Fe}_{3} \mathrm{O}_{4}$ preparadas y revestidas sobre zeolita natural $(\mathrm{CZ})(\mathrm{pH} 7$; $\mathrm{T}=20^{\circ} \mathrm{C}$ ). La capacidad máxima de adsorción fue 16.1 $\mathrm{mg} \mathrm{g}^{-1}$ y $24.9 \mathrm{mg} \mathrm{g}^{-1}$ para NZ y CZ, respectivamente. Sin embargo, los resultados mostraron que el aumento de iones de nitrato, carbonato y dureza disminuyó la eficiencia de eliminación de CEX en diferentes condiciones experimentales, como cambios de temperatura $\left(10-30^{\circ} \mathrm{C}\right)$ y variaciones de $\mathrm{pH}(3-11)$. Se descubrió que la capacidad de NZ mejoraba significativamente con la ayuda de recubrimiento con nanopartículas magnéticas de $\mathrm{Fe}_{3} \mathrm{O}_{4}$. Esto se debe al aumento en superficie y número de sitios activos en la CZ [87]. Como se muestra en la literatura, la cantidad de fármaco adsorbido por los diversos Al-Si crudos o no modificados es reducida [88]. También se demuestra que la polaridad de las moléculas adsorbidas y la naturaleza de la superficie sólida juegan un papel importante en la eficiencia de la adsorción.

Algunas zeolitas modificadas con HDTMA, identificadas como Surface Modified Zeolite (SMZ), han sido estudiadas para procesos de adsorción de cefalexina. Las SMZ sintetizadas se utilizaron evaluando los efectos de algunos parámetros como el grado de carga de HDTMA en la superficie de la zeolita, el pH de la solución, la dosis de SMZ, el tiempo de contacto, etc., concluyendo que las zeolitas modificadas con surfactante HDTMA mantienen una adsorción de la cefalexina a $\mathrm{pH}$ 12. Por otro lado, con base en los objetivos de la investigación se determinó que el proceso de desorción del antibiótico fue realizado a $\mathrm{pH}$ ácido $(\mathrm{pH} 2)$, debido a que en $\mathrm{pH}$ alcalino, la forma de carboxilato aniónico de la cefalexina tiene mayor fuerza de atracción con la cabeza positiva del tensoactivo HDTMA sobre SMZ [89].

El uso de imidazolato zeolítico para adsorción de ceftazidima (CAZ) mostró que la cantidad de adsorción de CAZ aumenta primero y luego disminuye con el incremento del contenido del agente CTAB (surfactante). En ese experimento se tuvo el mejor efecto de adsorción en CAZ cuando se agregó CTAB $0.1 \mathrm{mmol}$ y SL (siglas en inglés de laurato sódico) $0.1 \mathrm{mmol}$ como agentes molde [90]. Un agente molde o también conocido como Agente Director de Estructura (ADE), es un compuesto que ayuda a modificar las propiedades fisicoquímicas en la síntesis de zeolitas [91]. Su adición al gel de síntesis, en este caso, fue para ajustar el tamaño de poro. La cantidad de adsorción fue de solo $39.1 \mathrm{mg} \mathrm{g}^{-1}$ sin añadir agente molde y la cantidad de adsorción puede llegar hasta $74.25 \mathrm{mg}$ $\mathrm{g}^{-1}$ al agregar CTAB y SL. Estas características indican que puede ser un adsorbente a base de $\mathrm{Al}-\mathrm{Si}$ prometedor para la eliminación de CAZ de una solución acuosa ${ }^{[90]}$.

Las distintas modificaciones que pueden realizarse en la superficie de Al-Si y zeolitas abarcan desde el uso de surfactantes como HDTMA-Br, CTAB, óxidos de metales y nanopartículas, las cuales muestran diferentes capacidades de remoción (Tabla 2). 
TABLA 2

Remoción de Cefalosporinas con Aluminosilicatos Naturales y Modificados

\begin{tabular}{|c|c|c|c|c|}
\hline ANTibiótico & ADSORBENTE & ModificACIÓN & REMOCIÓN (mg/g) & REF. \\
\hline \multirow[t]{7}{*}{ Cefalexina } & Bentonita & No & 10.38 & {$[92]$} \\
\hline & Zeolita natural & No & 16.10 & [79] \\
\hline & Zeolita & $\mathrm{NP}$ de $\mathrm{MnO}_{2}$ & 24.5 & {$[79]$} \\
\hline & Óxido de manganeso $\mathrm{NP} *$ & No & 184.90 & {$[84]$} \\
\hline & Zeolita natural & No & 16.10 & {$[87]$} \\
\hline & Zeolita & $\mathrm{NP}$ de $\mathrm{Fe}_{3} \mathrm{O}_{4}$ & 24.9 & {$[87]$} \\
\hline & Zeolitas con surfactante & HDTMA-Br & $0.032 \mathrm{mmol}$ & {$[90]$} \\
\hline Cefexime & Óxido de manganeso NP & No & 171.60 & {$[84]$} \\
\hline \multirow[t]{2}{*}{ Ceftazidima } & Imidazolato zeolítico & No & 39.1 & {$[90]$} \\
\hline & Imidazolato zeolítico & $\mathrm{CTAB}+\mathrm{SL}$ & 74.25 & {$[90]$} \\
\hline
\end{tabular}

Después de una revisión completa sobre el uso de Al-Si para eliminar cefalosporinas del medio acuoso, se vislumbra que la importancia del uso de adsorbentes de bajo impacto ambiental para la adsorción de antibióticos se basa en la búsqueda de alternativas económicas y amigables con el ambiente para remover contaminantes emergentes.

En 2015, los residuos de demolición, minería y construcción, dentro de los cuales se encuentran los Al-Si, fueron considerados por el Programa de las Naciones Unidas para el Medio Ambiente (PNUMA) como la fuente de desechos más abundante y voluminosa, debido a que se generan anualmente en el mundo 7-10 000 millones de toneladas de Al-Si, lo cual representa el $36 \%$ del total de remanentes de la industria de demolición, minería y construcción [93].

Debido a las presiones ambientales y sociales por este tipo de residuos que contienen grandes cantidades de Al-Si, se han emprendido estrategias de gestión y tecnologías innovadoras para el reciclaje o reutilización de residuos de la construcción y minería como una solución prometedora. Esto se puede lograr valorizando los remanentes industriales para aplicaciones ambientales, como es el caso de la remoción de contaminantes orgánicos e inorgánicos de medio acuoso [94]. De esta forma, la modificación de materiales avanzados con tecnologías modernas puede generar productos factibles para los procesos de adsorción. Lo anterior se puede conseguir con ayuda de la nanotecnología mediante el aumento del área superficial, la obtención de adsorciones cinéticas más rápidas y el incremento en la capacidad de adsorción de los Al-Si [95].

\section{CONCLUSIONES}

La literatura revisada describe la presencia de diversos antibióticos considerados contaminantes emergentes en medios acuosos. Los antibióticos cefalosporínicos han sido señalados como precursores de resistencia bacteriana y su relación con los genes resistentes a los antibióticos que causan alteraciones en sistemas naturales.

Se han utilizado varios métodos para eliminar los antibióticos en medio acuoso, tales como electrólisis, oxidación avanzada, cloración y fotólisis, entre otros. Sin embargo, la adsorción es ampliamente utilizada porque es versátil y elimina diversos contaminantes sin generar subproductos. En plantas de tratamiento de aguas residuales que aplican métodos avanzados mediante adsorción, se utiliza el carbón activado como el adsorbente más común. Sin embargo, su costo y las dificultades asociadas con la regeneración ha contribuido al desarrollo de productos novedosos, entre los cuales se encuentran los materiales naturales o desechos industriales conocidos como adsorbentes de bajo costo.

Los adsorbentes con alto contenido inorgánico son habitualmente utilizados para la eliminación de contaminantes inorgánicos, especialmente de metales pesados. Sin embargo, la mayoría de los estudios sugieren el pretratamiento o modificación de algunos Al-Si para mejorar su capacidad de intercambio iónico, aumentar su área superficial y obtener propiedades específicas de adsorción para compuestos orgánicos como los antibióticos. Las modificaciones abarcan desde el uso de surfactantes como HDTMA-Br, CTAB, óxidos de metales y nanopartículas. 
Las zeolitas son un tipo de adsorbente específico y su especificidad depende principalmente del tamaño y forma de los poros del material, combinado con el tamaño y forma de la molécula objetivo.

Las referencias revisadas destacan a las zeolitas como un tipo de Al-Si que ha mostrado mayor capacidad de adsorción cuando son modificadas superficialmente con óxidos de metales o nanopartículas de metales, pero la modificación de Al-Si con surfactantes como el HDTMA-Br, CTAB o LS muestran la mayor capacidad de adsorción. Cabe mencionar que en la presente revisión, la información aún es limitada en lo que se refiere al diseño de adsorbentes y adsorbato (cefalosporinas) en específico.

En relación con las características de la molécula objetivo (cefalosporinas), los trabajos consultados utilizan cefalosporinas de primera y tercera generación, y la estructura de cada uno de los antibióticos es diferente, principalmente por las cadenas laterales presentes en su estructura básica.

La cefalexina es un antibiótico anfótero con grupos carboxílico y amina, los cuales pueden existir como un anión (en medio básico), un ion híbrido (en medio neutro) o un catión $\mathrm{H}$ (en medio ácido) que están en equilibrio.

Algunos tipos de cefalosporinas - por ejemplo, cefexime y ceftazidima, que contienen un aminotiazol y dos grupos carboxílicos- existen en medio ácido como catión o ion híbrido; en neutral y básico, como anión, o si es un cuaternario, el átomo de $\mathrm{N}$ está presente como un ion híbrido. Con la información anterior, es de esperarse que las condiciones de $\mathrm{pH}$ sean de vital importancia en el proceso de adsorción, ya que el medio de disociación dictará la afinidad que se obtenga en los sitios activos del adsorbente, así como la fuerza de adsorción.

Por último, se puede señalar que el uso de adsorbentes alternativos de bajo costo, como los aluminosilicatos (Al-Si) para la remoción de contaminantes orgánicos e inorgánicos, debe ser considerada una alternativa de bajo costo comparada con los adsorbentes convencionales. Asimismo, su aplicación como tecnología de tratamiento avanzado de aguas contaminadas conduce a un proceso inocuo y ambientalmente amigable que promueve el desarrollo sostenible y la mejora continua de la calidad del agua.

\section{REFERENCIAS}

[1] S. De Gisi, G. Lofrano, M. Grassi y M. Notarnicola, "Characteristics and adsorption capacities of low-cost sorbents for wastewater treatment: A review", Sustain. Mater. Technol., vol. 9, pp. 10-40, 2016, doi: 10.1016/j.susmat.2016.06.002.

[2] B. A. Rocha-Gutiérrez, M. R. Peralta-Pérez y F. J. Zavala-Díaz de la Serna, "Revisión global de los contaminantes emergentes PBDE y el caso particular de México", Rev. Int. Contam. Ambient., vol. 31, no. 3, pp. 311-320, 2015.

[3] O. Cárdenas, L. Navarro, P. Loeza, O. Del Río y R. Jiménez, "Perfiles de resistencia a antibióticos y metales pesados en Pseudomonas aeruginosa potencialmente patógenas aisladas de agua de uso agrícola", Rev. Electrónica Nov. Sci., vol. 9, pp. 97-112, 2017.

[4] M. Grassi, L. Rizzo y A. Farina, "Endocrine disruptors compounds, pharmaceuticals and personal care products in urban wastewater: Implications for agricultural reuse and their removal by adsorption process", Environ. Sci. Pollut. Res., vol. 20, no. 6, pp. 3616-3628, 2013, doi: 10.1007/s11356013-1636-7.

[5] G. Tchobanoglous, F. Burton y H. D. Stensel, "Wastewater engineering: An Overview”, en Wastewater Engineering - Treatment, Disposal and Reuse. Nueva York: McGraw-Hill Education, 1991, cap. 1, pp. 1-24.

[6] I. Ali, M. Asim y T. A. Khan, "Low cost adsorbents for the removal of organic pollutants from wastewater", J. Environ. Manage., vol. 113, pp. 170-183, 2012, doi: 10.1016/j.jenvman.2012.08.028.

[7] H. Blaak, G. Lynch, R. Italiaander, R. A. Hamidjaja, F. M. Schets y A. M. R. De Husman, "Multidrug-resistant and extended spectrum beta-lactamase-producing Escherichia coli in dutch surface water and wastewater", PLoS One, vol. 10, no. 6, pp. 1-16, 2015, doi: 10.1371/journal.pone.0127752.

[8] A. Y. C. Lin, T. H. Yu y S. K. Lateef, "Removal of pharmaceuticals in secondary wastewater treatment processes in Taiwan", J. Hazard. Mater., vol. 167, no. 1-3, pp. 1163-1169, 2009, doi: 10.1016/j.jhazmat.2009.01.108.

[9] CONAGUA, "Plantas de tratamiento de agua residual (nacional)”, SINA.conagua.gob.mx, 2019. Disponible: http://sina. conagua.gob.mx/sina/tema.php?tema=plantasTratamiento\&ver $=$ reporte $\& o=0 \& n=$ nacional (consultado: feb. 6, 2021). 
[10] S. E. Manahan, Introducción a la Química Ambiental. Barcelona: UNAM-Reverté Ediciones, S.A. de C.V., 2007, p. 320.

[11] E. Brillas, "A review on the degradation of organic pollutants in waters by UV photoelectro-fenton and solar photoelectro-fenton", J. Braz. Chem. Soc., vol. 25, no. 3, pp. 393-417, 2014, doi: 10.5935/0103-5053.20130257.

[12] S. J. T. Pollard, G. D. Fowler, C. J. Sollars y R. Perry, "Lowcost adsorbents for waste and wastewater treatment: a review", Sci. Total Environ., vol. 116, no. 1-2, pp. 31-52, 1992, doi: 10.1016/0048-9697(92)90363-W.

[13] D. Vukelic et al., "Eco-design of a low-cost adsorbent produced from waste cherry kernels", J. Clean. Prod., vol. 174, pp. 1620-1628, 2018, doi: 10.1016/j.jclepro.2017.11.098.

[14] M. Yoldi, E. G. Fuentes, S. A. Korili y A. Gil, “Zeolite synthesis from industrial wastes", Microporous Mesoporous Mater., vol. 287, pp. 183-191, 2019, doi: 10.1016/j.micromeso.2019.06.009.

[15] A. Peña-Álvarez, Araceli y Castillo-Alanís, "Identificación y cuantificación de contaminantes emergentes en aguas residuales por microextracción en fase sólida-cromatografía de gases-espectrometría de masas (MEFS-CG-EM)", TIP, vol. 18, no. 1, pp. 29-42, 2015, doi: 10.1016/j.recqb.2015.05.003.

[16] C. Jiménez-Cartagena, “Contaminantes orgánicos emergentes en el ambiente: Productos farmacéuticos", Rev. Lasallista Investig., vol. 8, no. 2, pp. 143-153, 2011.

[17] J. B. Ellis, "Pharmaceutical and personal care products (PPCPs) in urban receiving waters", Environ. Pollut., vol. 144, no. 1, pp. 184-189, 2006, doi: 10.1016/j.envpol.2005.12.018.

[18] T. Heberer, "Tracking persistent pharmaceutical residues from municipal sewage to drinking water", J. Hydrol., vol. 266, no. 3, pp. 175-189, 2002, doi: 10.1016/S0022-1694(02) 00165-8.

[19] B. Halling-Sørensen, S. Nors Nielsen, P. F. Lanzky, F. Ingerslev, H. C. Holten Lützhøft y S. E. Jørgensen, "Occurrence, fate and effects of pharmaceutical substances in the environment- A review", Chemosphere, vol. 36, no. 2, pp. 357-393, 1998, doi: 10.1016/S0045-6535(97)00354-8.

[20] F. Baquero, J.-L. Martínez y R. Cantón, "Antibiotics and antibiotic resistance in water environments", Curr. Opin. Biotechnol., vol. 19, no. 3, pp. 260-265, 2008, doi: 10.1016/j. copbio.2008.05.006.
[21] C. R. Ohoro, A. O. Adeniji, A. I. Okoh y O. O. Okoh, "Distribution and chemical analysis of pharmaceuticals and personal care products (PPCPs) in the environmental systems: A review", Int. J. Environ. Res. Public Health, vol. 16, no. 17, 2019, doi: 10.3390/ijerph16173026.

[22] B. J. Richardson, P. K. S. Lam y M. Martin, "Emerging chemicals of concern: pharmaceuticals and personal care products (PPCPs) in Asia, with particular reference to Southern China", Mar Pollut Bull, vol. 50, no. 9, pp. 913-920, 2005, doi: 10.1016/j.marpolbul.2005.06.034.

[23] M. D. Hernando, M. Mezcua, A. R. Fernández-Alba y D. Barceló, "Environmental Risk Assessment of Pharmaceutical Residues in Wastewater Effluents, Surface Waters and Sediments", Talanta, vol. 69, pp. 334-342, 2006, doi: 10.1016/j.talanta.2005.09.037.

[24] Z. Hoyett, "Pharmaceuticals and Personal Care Products: Risks, Challenges y Solutions", Risk Assess., 2018, doi: 10.5772/ intechopen.70799.

[25] M. Carballa et al., "Behavior of pharmaceuticals, cosmetics and hormones in a sewage treatment plant”, Water Res., vol. 38, no. 12, pp. 2918-2926, 2004, doi: 10.1016/j.watres.2004.03.029.

[26] J. Park et al., "Distribution and removal of pharmaceuticals in liquid and solid phases in the unit processes of sewage treatment plants", Int. J. Environ. Res. Public Health, vol. 17, no. 3, 2020, doi: 10.3390/ijerph17030687.

[27] M. Woolhouse, M. Ward, B. van Bunnik y J. Farrar, "Antimicrobial resistance in humans, livestock and the wider environment", Philos. Trans. R. Soc. B Biol. Sci., vol. 370, no. 1670, p. 20140083, jun. 2015, doi: 10.1098/rstb.2014.0083.

[28] C. Bouki, D. Venieri y E. Diamadopoulos, "Detection and fate of antibiotic resistant bacteria in wastewater treatment plants: A review", Ecotoxicol. Environ. Saf., vol. 91, pp. 1-9, 2013, doi: 10.1016/j.ecoenv.2013.01.016.

[29] A. Carattoli, "Animal reservoirs for extended spectrum $\beta$-lactamase producers", Clin. Microbiol. Infect., vol. 14, pp. 117-123, 2008, doi: 10.1111/j.1469-0691.2007.01851.x.

[30] L. C. Snow et al., "Risk factors associated with extended spectrum beta-lactamase Escherichia coli (CTX-M) on dairy farms in North West England and North Wales", Prev. Vet. Med., vol. 106, no. 3, pp. 225-234, 2012, doi: 10.1016/j. prevetmed.2012.03.009. 
[31] K. Veldman, A. Kant, C. Dierikx, A. van Essen-Zandbergen, B. Wit y D. Mevius, "Enterobacteriaceae resistant to third-generation cephalosporins and quinolones in fresh culinary herbs imported from Southeast Asia”, Int. J. Food Microbiol., vol. 177, pp. 72-77, 2014, doi: 10.1016/j.ijfoodmicro.2014.02.014.

[32] H. Blaak, P. de Kruijf, R. A. Hamidjaja, A. H. A. M. van Hoek, A. M. de Roda Husman y F. M. Schets, "Prevalence and characteristics of ESBL-producing E. coli in Dutch recreational waters influenced by wastewater treatment plants", Vet. Microbiol., vol. 171, no. 3, pp. 448-459, 2014, doi: 10.1016/j. vetmic.2014.03.007.

[33] L. Schages, F. Wichern, R. Kalscheuer y D. Bockmühl, "Winter is coming - Impact of temperature on the variation of beta-lactamase and mor genes in a wastewater treatment plant", Sci. Total Environ., vol. 712, 2020, doi: 10.1016/j. scitotenv.2020.136499.

[34] P. P. Amador, R. M. Fernandes, M. C. Prudêncio, M. P. Barreto y I. M. Duarte, "Antibiotic resistance in wastewater: Occurrence and fate of Enterobacteriaceae producers of Class A and Class C $\beta$-lactamases", J. Environ. Sci. Heal. Part A, vol. 50, no. 1, pp. 26-39, en. 2015, doi: 10.1080/10934529.2015.964602.

[35] M. Caltagirone et al., "Occurrence of Extended Spectrum $\beta$-Lactamases, KPC-Type y MCR-1.2-Producing Enterobacteriaceae from Wells, River Water, and Wastewater Treatment Plants in Oltrepò Pavese Area, Northern Italy", Frontiers in Microbiology, vol. 8, 2017, doi: 10.3389/fmicb.2017.02232.

[36] A. Endimiani, F. Perez y R. A. Bonomo, "Cefepime: a reappraisal in an era of increasing antimicrobial resistance", Expert Rev. Anti. Infect. Ther., vol. 6, no. 6, pp. 805-824, 2008, doi: 10.1586/14787210.6.6.805.

[37] D. Cacace et al., "Antibiotic resistance genes in treated wastewater and in the receiving water bodies: A pan-European survey of urban settings", Water Res., vol. 162, pp. 320-330, 2019, doi: 10.1016/j.watres.2019.06.039.

[38] X.-X. Zhang, T. Zhang y H. H. P. Fang, "Antibiotic resistance genes in water environment", Appl. Microbiol. Biotechnol., vol. 82, no. 3, pp. 397-414, 2009, doi: 10.1007/s00253-008-1829-z.

[39] I. George, P. Crop y P. Servais, "Fecal coliform removal in wastewater treatment plants studied by plate counts and enzymatic methods", Water Res., vol. 36, no. 10, pp. 2607-2617, 2002, doi: 10.1016/S0043-1354(01)00475-4.
[40] V. K. Gupta, P. J. M. Carrott y M. M. L. Ribeiro Carrott \& Suhas, "Low-Cost Adsorbents: Growing Approach to Wastewater Treatment-a Review", Crit. Rev. Environ. Sci. Technol., vol. 39, no. 10, pp. 783-842, 2009, doi: 10.1080/10643380801977610.

[41] H. B. Quesada, A. Takaoka Alves Baptista, L. F. Cusioli, D. Seibert, C. de Oliveira Bezerra y R. Bergamasco, "Surface water pollution by pharmaceuticals and an alternative of removal by low-cost adsorbents: A review", Chemosphere, vol. 222, pp. 766-780, 2019, doi: 10.1016/j.chemosphere.2019.02.009.

[42] E. Worch, Adsorption technology in water treatment. Fundamentals, Processes, and Modeling, 1. ${ }^{\mathrm{a}}$ ed. Berlín, Boston: De Gruyter, 2012.

[43] A. I. Liapis, Fundamentals of adsorption. New York: Engineering Foundation, 1987.

[44] D. A. Clifford, "Ion exchange and inorganic adsorption," en Water Quality and Treatment: A Handbook of Community Water Supplies, 5. ${ }^{\mathrm{a}}$ ed. Nueva York: Mc Graw-Hill, Inc., cap. 9, 1999.

[45] A. González-Ortiz, J. J. Ramírez-García y M. J. Solache-Ríos, "Kinetic and Thermodynamic Behavior on the Sorption of Clindamycin from an Aqueous Medium by Modified Surface Zeolitic Tuffs", Water. Air. Soil Pollut., vol. 229, no. 10, 2018, doi: 10.1007/s11270-018-3970-3.

[46] N. P. Cheremisinoff, Handbook of Water and Wastewater Treatment Technologies. Boston: Butterworth-Heinemann, 2002.

[47] W. K. Backhaus, E., Klumpp, H.-D. Narres y M. J. Schwuger, "Adsorption of 2,4-Dichlorophenol on Montmorillonite and Silica: Influence of Nonionic Surfactants", J. Colloid Interface, vol. 242, no. 1, 2001, doi: 10.1006/jcis.2001.7781.

[48] M. J. Martin, A. Artola, M. D. Balaguer y M. Rigola, "Activated carbons developed from surplus sewage sludge for the removal of dyes from dilute aqueous solutions", Chem. Eng. J., vol. 94, no. 3, pp. 231-239, 2003, doi: 10.1016/S1385-8947(03)00054-8.

[49] S. Rio, C. Faur-Brasquet, L. Le Coq, P. Courcoux y P. Le Cloirec, "Experimental design methodology for the preparation of carbonaceous sorbents from sewage sludge by chemical activation-application to air and water treatments", Chemosphere, vol. 58, no. 4, pp. 423-437, 2005, doi: 10.1016/j.chemosphere.2004.06.003. 
[50] R. K. Gautam, A. Mudhoo, G. Lofrano y M. C. Chattopadhyaya, "Biomass-derived biosorbents for metal ions sequestration: Adsorbent modification and activation methods and adsorbent regeneration", J. Environ. Chem. Eng., vol. 2, no. 1, pp. 239-259, 2014, doi: 10.1016/j.jece.2013.12.019.

[51] G. Crini, "Recent developments in polysaccharide-based materials used as adsorbents in wastewater treatment", Prog. Polym. Sci., vol. 30, no. 1, pp. 38-70, 2005, doi: 10.1016/j. progpolymsci.2004.11.002.

[52] J. Q. Jiang, N. J. D. Graham, C. M. André, G. H. Kelsall, N. P. Brandon y M. J. Chipps, "Comparative performance of an electrocoagulation/flotation system with chemical coagulation/dissolved air flotation: a pilot-scale trial”, Water Supply, vol. 2, no. 1, pp. 289-297, en. 2002, doi: 10.2166/ws.2002.0034.

[53] M. Piña-Soberanis, A. Martín-Domínguez, C. A. González-Ramírez, F. Prieto-García, A. Guevara-Lara y J. E. García-Espinoza, "Revisión de variables de diseño y condiciones de operación en la electrocoagulación”, Rev. Mex. Ing. Química, vol. 10, no. 2, pp. 257-271, 2011.

[54] J. R. Parga et al., "Arsenic removal via electrocoagulation from heavy metal contaminated groundwater in La Comarca Lagunera México", J. Hazard. Mater., vol. 124, no. 1-3, pp. $247-$ 254, 2005, doi: 10.1016/j.jhazmat.2005.05.017.

[55] N. Sapawe et al., "Cost-effective microwave rapid synthesis of zeolite NaA for removal of methylene blue", Chem. Eng. J., vol. 229, pp. 388-398, 2013, doi: 10.1016/j.cej.2013.06.005.

[56] B. A. Shah, H. D. Patel y A. V Shah, "Equilibrium and kinetic studies of the adsorption of basic dye from aqueous solutions by zeolite synthesized from bagasse fly ash", Environ. Prog. Sustain. Energy, vol. 30, no. 4, pp. 549-557, dic. 2011, doi: 10.1002/ ep. 10505.

[57] P. Gao, Y. Feng, Z. Zhang, J. Liu y N. Ren, "Comparison of competitive and synergetic adsorption of three phenolic compounds on river sediment”, Environ. Pollut., vol. 159, no. 10, pp. 2876-2881, 2011, doi: 10.1016/j.envpol.2011.04.047.

[58] J. J. Liu, X. C. Wang y B. Fan, "Characteristics of PAHs adsorption on inorganic particles and activated sludge in domestic wastewater treatment", Bioresour. Technol., vol. 102, no. 9, pp. 5305-5311, 2011, doi: 10.1016/j.biortech.2010.12.063.

[59] S. Chauhan y L. Pathania, "Impact of cationic surfactants on cefepime properties in aqueous medium: Micellization and characterization of microenvironment", J. Mol. Liq., pp. 953962, 2018, doi: 10.1016/j.molliq.2018.10.071.

[60] Y. Al-Degs, M. A. M. Khraisheh, S. J. Allen y M. N. A. Ahmad, "Sorption behavior of cationic and anionic dyes from aqueous solution on different types of activated carbons", Sep. Sci. Technol., vol. 36, no. 1, pp. 91-102, 2001, doi: 10.1081/SS100000853.

[61] W. A. Cabrera-Lafaurie, F. R. Román y A. J. Hernández-Maldonado, "Removal of salicylic acid and carbamazepine from aqueous solution with Y-zeolites modified with extraframework transition metal and surfactant cations: Equilibrium and fixed-bed adsorption", J. Environ. Chem. Eng., vol. 2, no. 2, pp. 899-906, 2014, doi: 10.1016/j.jece.2014.02.008.

[62] N. Jiang, R. Shang, S. G. J. Heijman y L. C. Rietveld, "High-silica zeolites for adsorption of organic micro-pollutants in water treatment: A review," Water Res., vol. 144, pp. 145-161, 2018, doi: 10.1016/j.watres.2018.07.017.

[63] S. Kesraoui-Ouki, C. R. Cheeseman y R. Perry, "Natural zeolite utilisation in pollution control: A review of applications to metals' effluents", J. Chem. Technol. Biotechnol., vol. 59, no. 2, pp. 121-126, 1994, doi: 10.1002/jctb.280590202.

[64] L. B. McCusker y C. Baerlocher, "Zeolite structures", en Introduction to Zeolite Science and Practice (Serie Studies in Surface Science and Catalysis, vol. 137), cap. 3. EUA: Elsevier, 2001, pp. 37-67, doi: 10.1016/s0167-2991(01)80244-5.

[65] X. Jia et al., "Heteroresistance to cefepime in Pseudomonas aeruginosa bacteraemia”, Int. J. Antimicrob. Agents, vol. 55, no. 3, mar. 2020, doi: 10.1016/j.ijantimicag.2019.10.013.

[66] J. Reungoat, J. S. Pic, M. H. Manéro y H. Debellefontaine, "Adsorption of Nitrobenzene from Water onto High Silica Zeolites and Regeneration by Ozone", Sep. Sci. Technol., vol. 42, no. 7, pp. 1447-1463, may. 2007, doi: 10.1080/01496390701289948.

[67] R. C. Bansal y M. Goyal, Activated Carbon Adsorption, 1. ${ }^{\mathrm{a}}$ ed. Nueva York: CRC Press, 2005.

[68] N. Jiang, R. Shang, S. G. J. Heijman y L. C. Rietveld, "Adsorption of triclosan, trichlorophenol and phenol by high-silica zeolites: Adsorption efficiencies and mechanisms", Sep. Purif. Technol., vol. 235, 2019, doi: 10.1016/j.seppur.2019.116152.

[69] C.-C. Wang, L.-C. Juang, C.-K. Lee, T.-C. Hsu, J.-F. Lee y H.P. Chao, "Effects of exchanged surfactant cations on the pore 
structure and adsorption characteristics of montmorillonite", J. Colloid Interface Sci., vol. 280, no. 1, pp. 27-35, 2004, doi: 10.1016/j.jcis.2004.07.009.

[70] N. Liu et al., "Sorption of tetracycline on organo-montmorillonites”, J. Hazard. Mater., vols. 225-226, pp. 28-35, jul. 2012, doi: 10.1016/j.jhazmat.2012.04.060.

[71] D. J. De Ridder, J. Q. J. C. Verberk, S. G. J. Heijman, G. L. Amy y J. C. Van Dijk, “Zeolites for nitrosamine and pharmaceutical removal from demineralised and surface water: Mechanisms and efficacy", Sep. Purif. Technol., vol. 89, pp. 71-77, 2012, doi: 10.1016/j.seppur.2012.01.025.

[72] S. Mella, C. Zemelman, H. Bello, M. Domínguez, G. González y R. Zemelman, "Propiedades microbiológicas, clasificación y relación estructura-actividad de cefalosporinas e importancia de las cefalosporinas de cuarta generación”, Rev Chil Infect, vol. 18, no. 1, pp. 7-19, 2001, doi: 10.4067/S071610182001000100002 .

[73] V. G. Alekseev, "Acid-base properties of penicillins and cephalosporins (a review)", Pharm Chem J, vol. 44, no. 1, pp. 14-24, 2010, doi: 10.1007/s11094-010-0389-6.

[74] S. Dancer, “The problem with cephalosporins", J Antimicrob Chemother, vol. 48, no. 4, pp. 463-478, 2001, doi: 10.1093/ jac/48.4.463.

[75] P. Ray, K. F. Knowlton, C. Shang y K. Xia, "Development and Validation of a UPLC-MS/MS Method to Monitor Cephapirin Excretion in Dairy Cows following Intramammary Infusion", PLoS One, vol. 9, no. 11, 2014, doi: 10.1371/journal.pone.0112343.

[76] S. Manzetti y R. Ghisi, "The environmental release and fate of antibiotics”, Mar. Pollut. Bull., vol. 79, nos. 1-2, pp. 7-15, 2014, doi: 10.1016/j.marpolbul.2014.01.005.

[77] E. López, D. Soy, M. T. Miana, C. Codina y J. Ribas, "Algunas reflexiones acerca de la administración de antibióticos betalactámicos en infusión continua", Enferm. Infecc. Microbiol. Clin., vol. 24, no. 7, pp. 445-452, 2006, doi: 10.1157/13091783.

[78] A. R. Ribeiro, B. Sures y T. C. Schmidt, "Cephalosporin antibiotics in the aquatic environment: A critical review of occurrence, fate, ecotoxicity and removal technologies", Environ. Pollut., vol. 241, pp. 1153-1166, 2018, doi: 10.1016/j. envpol.2018.06.040.
[79] M. R. Samarghandi, T. J. Al-Musawi, A. Mohseni-Bandpi y M. Zarrabi, "Adsorption of cephalexin from aqueous solution using natural zeolite and zeolite coated with manganese oxide nanoparticles", J. Mol. Liq., vol. 211, pp. 431-441, 2015, doi: 10.1016/j.molliq.2015.06.067.

[80] D. A. C. Coledam et al., "Electrochemical mineralization of cephalexin using a conductive diamond anode: A mechanistic and toxicity investigation", Chemosphere, vol. 168, pp. 638-647, feb. 2017, doi: 10.1016/j.chemosphere.2016.11.013.

[81] N. Ajoudanian y A. Nezamzadeh-Ejhieh, "Enhanced photocatalytic activity of nickel oxide supported on clinoptilolite nanoparticles for the photodegradation of aqueous cephalexin", Mater. Sci. Semicond. Process., vol. 36, pp. 162-169, ag. 2015, doi: 10.1016/j.mssp.2015.03.042.

[82] X. He, S. P. Mezyk, I. Michael, D. Fatta-Kassinos y D. D. Dionysiou, "Degradation kinetics and mechanism of $\beta$-lactam antibiotics by the activation of $\mathrm{H}_{2} \mathrm{O}_{2}$ and $\mathrm{Na}_{2} \mathrm{~S}_{2} \mathrm{O}_{8}$ under UV-254 nm irradiation", J. Hazard. Mater., vol. 279, pp. 375-383, ag. 2014, doi: 10.1016/j.jhazmat.2014.07.008.

[83] M. Jiang, L. Wang y R. Ji, "Biotic and abiotic degradation of four cephalosporin antibiotics in a lake surface water and sediment", Chemosphere, vol. 80, no. 11, pp. 1399-1405, sept. 2010, doi: 10.1016/j.chemosphere.2010.05.048.

[84] A. Fakhri y S. Adami, "Adsorption and thermodynamic study of Cephalosporins antibiotics from aqueous solution onto MgO nanoparticles", J. Taiwan Inst. Chem. Eng., vol. 45, no. 3, pp. 1001-1006, may. 2014, doi: 10.1016/j.jtice.2013.09.028.

[85] L. Li, D. Wei, G. Wei y Y. Du, “Transformation of cefazolin during chlorination process: products, mechanism and genotoxicity assessment", J. Hazard. Mater., vol. 262, pp. 48-54, nov. 2013, doi: 10.1016/j.jhazmat.2013.08.029.

[86] J. W. Peterson, T. A. O’Meara, M. D. Seymour, W. Wang y B. $\mathrm{Gu}$, "Sorption mechanisms of cephapirin, a veterinary antibiotic, onto quartz and feldspar minerals as detected by Raman spectroscopy", Environ. Pollut., vol. 157, no. 6, pp. 1849-1856, 2009, doi: 10.1016/j.envpol.2009.01.017.

[87] A. Mohseni-Bandpi, T. J. Al-Musawi, E. Ghahramani, M. Zarrabi, S. Mohebi y S. A. Vahed, "Improvement of zeolite adsorption capacity for cephalexin by coating with magnetic $\mathrm{Fe}_{3} \mathrm{O}_{4}$ nanoparticles", J. Mol. Liq., vol. 218, pp. 615-624, 2016, doi: 10.1016/j.molliq.2016.02.092. 
Z. M. Rivera-Pérez et al. Remoción de cefalosporinas con aluminosilicatos ARTÍCULO DE REVISIÓN

[88] T. Farías, A. R. Ruiz-Salvador y A. Rivera, "Interaction studies between drugs and a purified natural clinoptilolite", Microporous Mesoporous Mater., vol. 61, nos. 1-3, pp. 117-125, 2003, doi: 10.1016/S1387-1811(03)00391-3.

[89] A. Nezamzadeh-Ejhieh y S. Tavakoli-Ghinani, "Effect of a nano-sized natural clinoptilolite modified by the hexadecyltrimethyl ammonium surfactant on cephalexin drug delivery", Comptes Rendus Chim., vol. 17, no. 1, pp. 49-61, 2014, doi: 10.1016/j.crci.2013.07.009.

[90] H. Duan, X. Hu y Z. Sun, "Magnetic zeolite imidazole framework material-8 as an effective and recyclable adsorbent for removal of ceftazidime from aqueous solution", J. Hazard. Mater., vol. 384, 2020, doi: 10.1016/j.jhazmat.2019.121406.

[91] J. M. Martinez-Blanes, "Obtención de zeolitas utilizando líquidos iónicos como agentes directores de estructura", tesis de doctorado. Depto. de Química Inorgánica, Universidad de Sevilla, Sevilla, España, 2015.
[92] R. S. Al-Khalisy, A. M. A. Al-Haidary y A. H. Al-Dujaili, "Aqueous Phase Adsorption of Cephalexin onto Bentonite and Activated Carbon”, Sep. Sci. Technol., vol. 45, no. 9, pp. 12861294, may. 2010, doi: 10.1080/01496391003689017.

[93] Y. Su, H. Si, J. Chen y G. Wu, "Promoting the sustainable development of the recycling market of construction and demolition waste: A stakeholder game perspective”, J. Clean. Prod., vol. 277, 2020, doi: 10.1016/j.jclepro.2020.122281.

[94] R. Islam, T. H. Nazifa, A. Yuniarto, A. S. M. Shanawaz Uddin, S. Salmiati y S. Shahid, "An empirical study of construction and demolition waste generation and implication of recycling", Waste Manag., vol. 95, pp. 10-21, 2019, doi: 10.1016/j. wasman.2019.05.049.

[95] N. Zhang et al., "Recent investigations and progress in environmental remediation by using covalent organic framework-based adsorption method: A review", J. Clean. Prod., vol. 277, 2020, doi: 10.1016/j.jclepro.2020.123360. 